\title{
DESIGN OF TRANSMISSION SYSTEM FOR A HYBRID VEHICLE
}

\author{
D. BHASKAR, P. SIVAKUMAR, VINAY ATGUR, RISHITHA LAKKAKULA,
}

\section{LAKSHMI VENKATESH PARAGOTI \& N. H. S. VENKAT SAI}

Assistant Professor, Department of Mechanical Engineering, Koneru Lakshmaih Educational Foundation,

Guntur, Andhra Pradesh, India

\section{ABSTRACT}

Conventional vehicles use gasoline or diesel to power an internal combustion engine which produces harmful gases into the environment. The best way to overcome this problem is by using a hybrid vehicle. The goal of a hybrid vehicle which is a rear wheel drive powered by both electric motor and IC engines to maximize the performance of the vehicle in supplying maximum power to the wheels independently from both electric motor and IC engine, which is the parallel type of transmission. To provide the proper transmission system in the hybrid vehicle it is capable of effectively transfer motion from the engine to the wheels and also acts as Eco-friendly. Efficient by maximizing performance output with minimal power losses. Compared with the battery electric vehicle, the available conventional internal combustion engine generates the power, together with the battery, the motor-driven hybrid electric vehicle, after filling the oil and the electricity, can travel about 500 1000 kilometers. When the hybrid electric vehicle decelerates and brakes, the drive motor transforms into the generator, it will change the braking energy into the electrical energy, feeding back to the power battery, causing the deceleration and the braking energy recycled. The present work includes analysis, of resistance parameters, acceleration, and gradability.

KEYWORDS: Engine Layout, Gearbox, Electric Motor, Rolling Resistance, Aerodynamic Resistance \& Gradability

Received: Feb 27, 2018; Accepted: Mar 19, 2018; Published: Apr 09, 2018; Paper Id.: IJMPERDAPR2018153

\section{INTRODUCTION}

The drivetrain of hybrid vehicle transmits power to the driving wheels of the vehicle. A hybrid vehicle has various forms of motive power the Powertrain includes all the components used to transform stored potential energy power sources for the hybrid vehicle may either use coal, compressed natural gas, gasoline, diesel, flywheel, hydrogen, solar, wind, electric batteries, hydraulic accumulator etc. ${ }^{[1]}$ Transmission is one of the most important and vital systems in one of the automobile. It is a combination of different components which varies from one automobile to another automobile according to needs and requirements of a particular usage ${ }^{[2]}$. They are many components involved in it. Some important components are engine, gearbox, clutch etc. There are different types of hybrid which are being used in our daily life. Based on the design there are i) parallel hybrid have both IC engine and an electric motor that can both individually run the car or being coupled. ii) Series hybrid is an extended range electric vehicle. iii) power split hybrid is the parallel hybrids that incorporate power split devices ${ }^{[3]}$. Based on hybridization there are micro-hybrids, mild hybrids, full hybrids, and plug-in hybrids. 


\section{ENGINE LAYOUT}

The type of transmission design which is suitable for the car is the parallel drive. The engine system design is given in figure1:

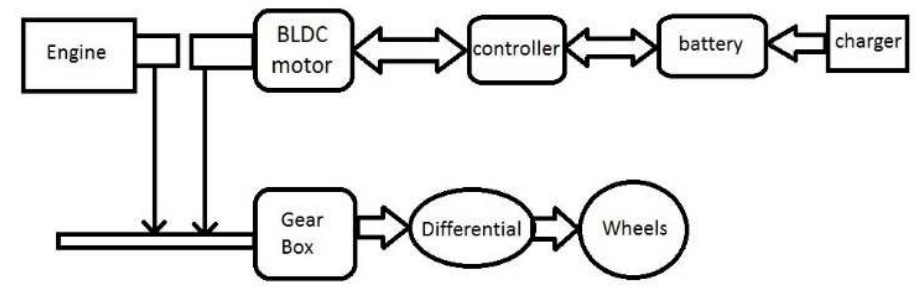

Figure 1: Layout of Engine Design

In this, both IC engine and electric motor work constantly to get more power.

\section{WORKING PRINCIPLE}

The engine supplies energy to the gearbox input shaft through a chain drive. Similarly the DC motor draws power from the battery connected to it and supplies it to the shaft through another chain drive, where both of the motor and IC engine are connected to gearbox input shaft through sprockets provided with single direction lock which adds an advantage of using both the IC engine and electric motor in powering the vehicle independently along with power multiplication of both IC engine and electric motor that is being transmitted to the wheels Then the power is transmitted through differential to the wheels [4-5].

\section{ENGINE}

The major component of the entire transmission system and the heart of the vehicle is an engine which acts as an input to the entire system of the transmission [6]. It is also called as a driven component. According to the current analysis, Briggs and Stratton 1450XR Engine is used.

The specification of the engine is mentioned below

Table 1: Specifications of the Engine

\begin{tabular}{|l|c|}
\hline Model Number & 19N1 \\
\hline Engine Displacement(cc) & 306cc \\
\hline Power & 10HP@3600RPM \\
\hline Torque & $19.5 \mathrm{Nm} @ 2800 \mathrm{RPM}$ \\
\hline Number of cylinders & Gasoline \\
\hline Fuel Type & 5W-30 \\
\hline Engine oil grade &
\end{tabular}




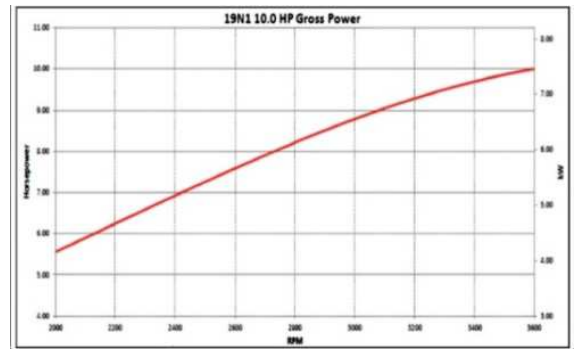

Figure 2: Power vs RPM Graph

\subsection{Engine Power}

Engine power which is also termed as horsepower is the maximum power of an engine output. Expressed in the form of kilowatts or horsepower [7]. The output power depends upon the size and design of the engine. It is also based on the speed and the applied load and torque.

Engine Power $=\frac{(\text { Engine Rpm } \times \text { Torque }(\mathrm{ft}-\mathrm{lbs}))}{5252}=10 \mathrm{HP}$

The power output of the engine is 10HP@ 3600 RPM.

\section{ELECTRIC MOTOR}

As it is a hybrid model of the vehicle, the electric motor has been used. The electrical motor used is a BLDC motor $2 \mathrm{KW}$. The specification of a motor is given below

Table 2: Specifications of the Motor

\begin{tabular}{|l|l|}
\hline Model number & BLDC125/5D \\
\hline Power & $2 \mathrm{KW}$ \\
\hline Continuous Torque & $8 \mathrm{Nm}$ \\
\hline Peak Torque & $24 \mathrm{Nm}$ \\
\hline DC Voltage & $48 \mathrm{~V}$ \\
\hline Rated Current & $35 \mathrm{Amp}$ \\
\hline Peak Current & $80 \mathrm{Amp}$ \\
\hline
\end{tabular}

\section{GEARBOX}

The gearbox is the one of the foremost components in deciding the performance of the vehicle. The main function of the gearbox is to vary the torque and power from one gear to another gear [8]. By this phenomenon, it will give the flexibility to drive the vehicle and make the vehicle ready for all the conditions. The gearbox used is a customize gear box and the gear ratios are derived from the calculation by considering all the factors that are restricting the motion of the vehicle. The major advantage of this type of gearbox is that it is designed and manufactured according to the need and requirement. This gives the complete control over the vehicle and drives according to our need [9]. The required calculation of the gear ratios is mentioned below

- $\quad$ First gear ratio: -4.66

- $\quad$ Second gear ratio: -3.117

- $\quad$ Third gear ratio: -2.136

- Fourth gear ratio: - 1.41 


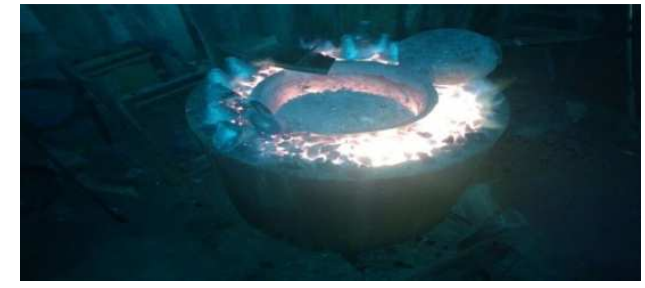

Figure 3: Manufacturing of Gearbox

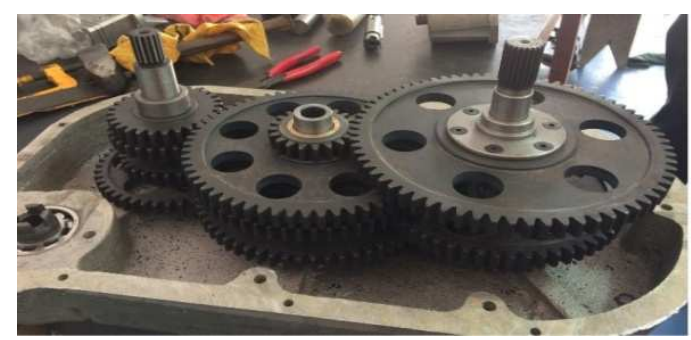

Figure 4: Final Output of a Gearbox

\subsection{Required Torque on Wheels}

To get the required torque to move the car the following calculations are required to perform. The following steps will give the torque at each drive wheel. So, the required steps are:

- $\quad$ Rolling Resistance (RR)

- $\quad$ Grade Resistance (GR)

- $\quad$ Aerodynamic Resistance (AR)

We assume that

The mass of the vehicle $=275 \mathrm{Kg}$

Driver weight $=75 \mathrm{Kg}$

Gross weight of the vehicle $=350 \mathrm{Kg}(3432.32 \mathrm{~N})$

\subsubsection{Rolling Resistance (RR)}

The force which required to overcome the rolling friction of a wheel is called as rolling resistance.

Rolling Resistance $(\mathrm{RR})=$ Gross weight $(\mathrm{GVW}) \times$ Surface Friction $(\mathrm{Fr})$

$\mathrm{RR}=\mathrm{GVW} \times \mathrm{Fr}$

$\mathrm{RR}=3432.32 \times 0.022=1716.16 \mathrm{~N}$

\subsubsection{Grade Resistance (GR)}

The force required to climb an inclination on the road is called as Grade resistance.

Grade Resistance $(\mathrm{GR})=$ Gross weight $(\mathrm{GVW}) \times \operatorname{Sin} \alpha$

$\mathrm{GR}=3432.32 \times \operatorname{Sin}(2.3)$

$\mathrm{GR}=137.79 \mathrm{~N}$ 


\subsubsection{Aerodynamic Resistance (AR)}

It is also called as drag force that acts parallel and opposite to the direction of flow exerted by the air on an object.

Aerodynamic Resistance $(A R)=\left(\frac{1}{2}\right) \rho \mathbf{v}^{2} A C d$

$A R=\left(\frac{1}{2}\right) \mathbf{1 . 1 2 5} * \mathbf{1 . 3 8 8 9} * 0.8 * 0.57$

$\mathrm{AR}=0.49 \mathrm{~N}$

Total Road Load $=\mathrm{RR}+\mathrm{AR}+\mathrm{GR}$

$$
\begin{aligned}
& =1716.16+137.79+0.49 \\
& =1855.032 \mathrm{~N}
\end{aligned}
$$

Tractive Effort $=3432.32 * \cos (0) * 0.4=1372.928 \mathrm{~N}$

Maximum tractive effort is taken by considering all the friction losses

Therefore, Maximum Tractive effort

$$
\begin{aligned}
& =\text { Tractive effort } * 1.15 \\
& =1372.928 * 1.15 \\
& =1578.8672 \mathrm{~N}
\end{aligned}
$$

Torque Required at Wheel $(\mathrm{Tw})=$ Total Road Load* Dynamic Rolling Radius

$$
\mathrm{Tw}=214.972 * 0.2413=51.87 \mathrm{~N}-\mathrm{m}
$$

\subsection{Acceleration}

Acceleration is the rate of change of velocity of an object with respect to time.

Acceleration $=$ Tractive effort $/$ Gross weight

$$
\begin{aligned}
& =\frac{1444.032}{320} \\
& =4.512 \mathrm{~m} / \mathrm{s}^{2}
\end{aligned}
$$

\subsection{Maximum Speed}

$$
\begin{aligned}
\mathrm{V}_{\text {max }} & =\frac{(\mathrm{RPM} * \pi * \times \text { DIA }(\mathrm{ft}))}{(\text { DIFF RATIO } * \text { FINAL GEAR RATIO } * 88)} \\
& =\frac{3600 * 3.14 * 1.583}{2.136 * 2.667 * 88} \\
& =54.101 \mathrm{MPH} \\
& =87.067 \mathrm{KMPH}
\end{aligned}
$$

\subsection{Gradability}

Gradability is defined as the highest grade a vehicle can ascend maintaining at a particular speed. 
It is measured in multiple ways, mainly:

- At an angle of inclination to the horizontal $\left(20^{\circ}, 30^{\circ}, 45^{\circ}\right.$, etc. $)$.

- As a percentage of rising overrun.

- As a ratio of one part run to some number of parts

$$
\begin{aligned}
P & =\left[\frac{F z}{9.81 G z}-F_{R}\right] \\
& =\left[\frac{1444.032}{9.81 \times 320}-0.02\right]=43.2 \%
\end{aligned}
$$

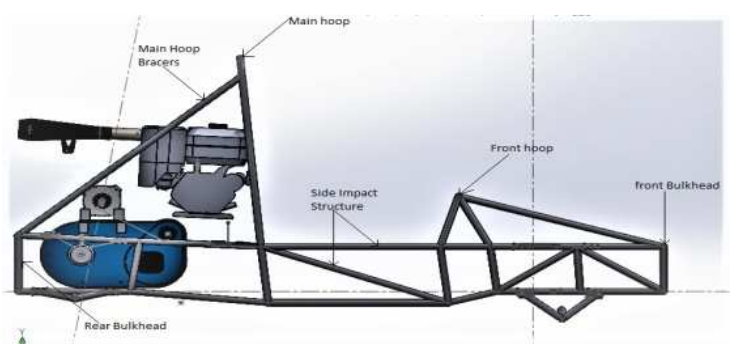

Figure 5: Installation of Power Train

\section{RESULTS AND DISCUSSIONS}

Based on the experimental and theoretical calculation, the design of the gearbox and installation of all the components had been done. As per the design the first gear ratio is 4.66 which gives the speed of $26.41 \mathrm{kmph}$ from Engine and $20.11 \mathrm{kmph}$ from motor, second gear 3.117 which gives the speed of $39.41 \mathrm{kmph}$ from theengine and 31.33 from motor, the third gear ratio is 2.136 which gives the speed of $57.63 \mathrm{kmph}$ from engine and $45.7 \mathrm{kmph}$ from the motor and the final gear ratio is 1.41 which gives the speed of $87.3 \mathrm{kmph}$ from engine and $67.12 \mathrm{kmph}$ from motor [10-11]. Finally, it is observed that by varying the gear ratio speed of the vehicle is also varied, but the friction comes out to be $1902.95 \mathrm{~N}$.

Table 3: Speed at Different Gears: (Engine)

\begin{tabular}{|c|c|c|}
\hline Gear & Gear Ratio & Speed(KMPH) \\
\hline $1^{\text {st }}$ & 4.66 & 26.41 \\
\hline $2^{\text {nd }}$ & 3.117 & 39.49 \\
\hline $3^{\text {rd }}$ & 2.136 & 57.63 \\
\hline $4^{\text {th }}$ & 1.41 & 87.30 \\
\hline
\end{tabular}

Table 4: Torque and Rpm: (Engine)

\begin{tabular}{|c|c|c|}
\hline Gear & RPM at Wheels & Torque(Nm) \\
\hline $1^{\text {st }}$ & 290.42 & 243.69 \\
\hline $2^{\text {nd }}$ & 434.193 & 162.98 \\
\hline $3^{\text {rd }}$ & 633.604 & 111.69 \\
\hline $4^{\text {th }}$ & 959.843 & 73.72 \\
\hline
\end{tabular}

Table 5: Speed at Different Gears: (Motor)

\begin{tabular}{|c|c|c|}
\hline Gear & Gear Ratio & Speed(KMPH) \\
\hline $1^{\text {st }}$ & 4.66 & 20.11 \\
\hline $2^{\text {nd }}$ & 3.117 & 31.33 \\
\hline $3^{\text {rd }}$ & 2.136 & 45.7 \\
\hline $4^{\text {th }}$ & 1.41 & 67.12 \\
\hline
\end{tabular}




\section{CONCLUSIONS}

A Hybrid Powertrain had been powered parallelly by the engine and the motor. As it is designed as per the proved results the maximum speed and maximum fuel economy has been attained. When there is need of maximum torque and for eco-friendly, the gearbox uses the source of motor, whereas for getting maximum speed engine is used. It is capable of effectively transfer motion from the engine to the wheels and Efficient by maximizing performance output with minimal power losses.

\section{REFERENCES}

1. K. M. Rahman, B. Fahimi, G. Suresh, A. V. Rajaratnam, M. Ehsani, "Advanced of switched reluctance motor applications to EV and HEV: Design and control issues", IEEE Trans. Industry Applic., vol. 36, no. 1, pp. 111-121, Jan./Feb. 2000

2. K. M. Rahman, M. Ehsani, "Performance analysis of electric motor drives for electric and hybrid electric vehicle application", Power Electron. Transportation, pp. 49-56, 1996.

3. M. Ehsani, Y. Gao, S. Gay, A. Amade, Modern Electric Hybrid Electric, and Fuel Cell Vehicles: Fundamentals Theory and Design, FL, Boca Raton: CRC, Nov. 2004.

4. T. Kume, T. Iwakane, T. Yoshida, I. Nagai, "A wide constant power range vector-controlled ac motor drive using winding changeover technique", IEEE Trans. Industry Applic., vol. 27, no. 5, pp. 934-939, Sept./Oct. 1991.

5. Wang S. M., 1974, Analysis of Nonlinear Transient Motion of a Geared Torsional, Journal of Engineering for Industry, Transactions of the ASME, February

6. A. Hema Sekhar \& A. Lakshmi Devi, Performance of Transmission System using Firing Angle Model of SVC by Conventional Method, International Journal of Electrical and Electronics Engineering Research (IJEEER), Volume 6, Issue 5, September October 2016, pp. 33-46

7. Mark W. D., 1978, Analysis of the Vibratory Excitation of Gear Systems: Basic Theory, J. Acoust. Soc. Am., 63, 5, 1409-1430

8. Bartelmus W., 1992, Vibration Condition Monitoring of Gearboxes, Machine Vibration, 1, Springer-Verlag London Limited, 178-189

9. Zhi-Ping Lin, Her-Shing Wang \& Shao-Jyun Tsai, The Intelligent Charging Path Planning for Electric Vehicle, International Journal of Computer Networking, Wireless and Mobile Communications (IJCNWMC), Volume 6, Issue 3, May - June 2016, pp. 1-8

10. Dąbrowski Z., 1992, The Evaluation of the Vibroacoustic Activity for Needs of Constructing and Use of Machines, Machine Dynamics Problems, 4, Warsaw University of Technology

11. B. Tryon, "Hybrid Electric Vehicle Energy Management System," US Patent 2005/0228553, 2005

12. C. Rosenkranz, "Plug in hybrid batteries," presented at the EVS20: The 20th International Electric Vehicle Symposium and Exhibition, Long Beach, CA, 2003.

13. J. O. Manyala, T. Fritz, Z. A. Massood, "Integration of tri-axial Hall effect sensor technology for gear position sensing in commercial vehicle transmissions", IEEE Trans. Instrum. Meas., vol. 61, pp. 664-672, Mar. 2012. 
